\title{
Rekonstruktion von Gletscherschwankungen mit Hilfe fossiler Hölzer
}

\section{Einleitung}

Für die Rekonstruktion der Gletschergeschichte können verschiedene Methoden herangezogen werden. Einerseits wertet man historisches Quellenmaterial aus, nämlich Bildmaterial (Zeichnungen, Aquarelle, Gemälde, Stiche und Photographien) und schriftliche Aufzeichnungen (alte Dokumente wie Bittgesuche und Alprechtsverträge, Reiseberichte, frühe wissenschaftliche Arbeiten und Vermessungsergebnisse der Gletscherkommission). Andererseits basieren unsere Resultate - vor allem was den Zeitraum vor $1600^{1}$ betrifft - auf der Datierung von organischem Material aus dem Gletschervorfeld ${ }^{2}$ wie fossile Böden und fossile Hölzer (vgl. SCHNEEBELI 1976, RÖTHLISBERGER F. 1976), das im Moränenschutt Jahrhunderte oder gar Jahrtausende überdauert hat.

Auch das Auswerten von geländearchäologischen Spuren ist vielfach sehr aufschlußreich, beispielsweise das Auswerten ehemals begangener Wege in der näheren Umgebung von Gletschern: Führt ein Weg nur bei großer Gletscherausdehnung über das Eis, so zwingt ein Gletscherschwund zur Aufgabe des Weges. Es können häufig Wegspuren bis an den Rand des Gletschervorfeldes zu den Hochstandsmoränen verfolgt werden, wo sie plötzlich enden. Umgekehrt haben Gletscher in Vorstoßphasen Wege teilweise zerstört und diese ungangbar gemacht (RÖTHLISBERGER F. 1976: 116, 117; HOLZHAUSER Und WETTER 1982: 58). Hauptsächlich im Wallis können verfallene Wasserleitungen, deren Wasserfassungen einst in unmittelbarer Nähe eines Gletschers lagen, Aufschluß über ehemalige Gletscherausdehnungen geben. Das Bestehen einer solch gletschernahen Fassung hing in hohem Maße von der Bewegung des Eisstromes ab: Ein Gletschervorstoß schnitt die Wasserzufuhr ab, oder aber das Wasser versiegte während eines Gletscherschwundes.

In diesem Artikel ist die Rede von einer dererwähnten Methoden, nämlich vom Auswerten fossiler Hölzer aus dem Vorfeld des Großen Aletschgletschers. Die Resultate sind meiner Dissertation entnommen, die unter der Leitung von Herrn Professor Dr. G. Furrer am Geographischen Institut der Universität Zürich entstanden ist.

\section{Fossile Hölzer aus dem Gletschervorfeld}

Während des Postglazials, im Laufe der letzten rund 10000 Jahre, stießen die Gletscher mehrfach vor und erreichten oft Ausdehnungen wie bei den neuzeitlichen Gletscherhochständen um 1600/1650 und um 1820/1850 (vgl. GAMPER und SUTER 1982: 105-114). Die Eisströme bedeckten mit ihren Eismassen und dem mitgeführten Schutt häufig vegetationsbedecktes Gebiet; in tieferen Lagen drangen sie mit ihrer Zunge sogar in den Wald ein, stießen Bäume um und überfuhren sie anschließend.

Vor allem aus der ersten Hälfte des 19. Jahrhunderts, als die Alpengletscher sich erneut kräftig ausdehnten zum letzten neuzeitlichen Hochstand, datieren Berichte von Verwüstungen durch vorstoßende Gletscher, die einzelne Bäume und ganze Waldbestände unter sich begruben. So schreibt AGASSIZ (1840: 233), daß der Brenvagletscher, bevor er 1820 wieder etwas abzuschmelzen begann, die Reste einer alten Kapelle bedeckte und bis zu 220jährige Lärchen umstie $\beta^{3}$. Auch der Zmuttgletscher ist nach COLLOMB (1849: 39) im Jahre 1848 derart vorgestoßen, daß er einen Lärchenbestand von zirka 300 Jahre alten Bäumen überfuhr. Einer anderen Textstelle im selben Werk von COLlOMB (1849: 34) ist zu entnehmen, daß ebenfalls um die Mitte des 19. Jahrhunderts der Große Aletschgletscher stark anschwoll und sowohl seitlich als auch mit seiner Stirn hochstämmigen Wald niederwalzte. Dieser Vorgang ist von CollomB sehr gut beobachtet und beschrieben worden und enthält bemerkenswerte Angaben:

"Sur la rive gauche il (der Große Aletschgletscher, eigene Anm.) est bordé par une chaîne de montagnes qui fait suite à l'Aeggishorn, ces montagnes sont couvertes en partie d'une forêt de sapins très-compacte, et sur 4 kilom. de longueur mesurés en partant du talus terminal en amont, le glacier ravage et détruit une grande quantité de ces sapins. La moraine latérale gauche les atteint, les

Hanspeter Holzhauser, dipl. Geograph,

Geographisches Institut der Universität Zürich-Irchel, Winterthurerstr. 190, 8057 Zürich 
attaque d'abord par les racines, puis, l'arbre tombe, et se trouve entraîné par le mouvement des glaces. Ceux qui sont pris entre la glace et la roche encaissante sont promptement déchirés, ceux qui tombent à la surface prennent part au mouvement général, mais ils ne tardent pas à être entraînés sous le glacier.

Au talus terminal on les voit sortir de dessous les masses de glace, les uns à moitié engagés, d'autres complétement libres, ceux-ci sont expulsés et précipités dans le torrent; tous ces arbres sont entièrement décortiqués et déchirés, il n'en reste que le tronc principal et quelques fortes branches pliées et contournées."

Durch den massiven Gletscherschwund, der nach dem letzten Gletscherhochstand um 1850 einsetzte und bis heute - unterbrochen von einzelnen kurzfristigen Wiedervorstößen um 1890 und um 1920 andauert, kommen in einigen Gletschervorfeldern immer wieder fossile Wurzelstöcke und fossile Baumstämme zum Vorschein. Im Stirnbereich des Großen Aletschgletschers entdeckte CORREVON im Jahre 1901 (zit. in FOREL 1902: 209) Reste eines ehemaligen Lärchenwaldes. Später berichtet HEss (1935: 288) von fest verwurzelten und oberflächlich abgeschliffenen Wurzelstöcken am selben Fundort, die im Jahre 1920 noch unter dem Eise lagen. Im selben Artikel beschreibt und interpretiert HESS ausführlich fossile Holzfunde am Findelengletscher. In den folgenden Jahren fand MARIETAN (1935/36: 45-50) am Unteraargletscher, innerhalb des Gletschervorfeldes, in einer Felsritze Wurzeln einer Bergföhre. Auf weitere Holzfunde weist MARIETAN (1952: 94-96) in einem später erschienenen Artikel hin.

Seit der Einführung der Radiokarbonmethode (kurz ${ }^{14} \mathrm{C}$-Methode genannt) durch LIBBY (1952) besteht die Möglichkeit, organisches Material zu datieren. Wir verfügen so über eine Methode, Gletschervorstöße zeitlich einzustufen. Ohne eine solche Datierungsmöglichkeit wären wir heute noch genau in derselben Lage wie damals COLLOMB am Unteraargletscher, der von den gefundenen Holzresten nur aussagen konnte, daß sie sehr alt sein müssen.

Mit der Datierung von fossilem Holz durch die ${ }^{14} \mathrm{C}$ Methode ist es dann OESCHGER und RÖTHLISBERGER H. (1961) gelungen, einen Vorstoß des Großen Aletschgletschers um 1200 nachzuweisen. Da die Hölzer in situ entnommen werden konnten, sind die Resultate sehr aussagekräftig bezüglich der Gletscherausdehnung vor und während des betreffenden Vorstoßes. Mit Hilfe der Dendrochronologie, insbesondere der in jüngster Zeit entwickelten Radiodensitometrie, können Klimaschwankungen aufgrund des Jahrringmusters fossiler als auch rezenter Bäume erkannt werden (RÖTHLISBERGER F. 1976; SCHWEINGRUBER et al. 1978, SCHWEINGRUBER 1983, RENNER 1982). In günstigen Fällen lassen sich fossile Hölzer aus Gletschervorfeldern absolut datieren, das heißt, der Absterbezeitpunkt kann in Kalenderjahren ange- geben werden, und somit ist auch der Zeitpunkt des Gletschervorstoßes über den Fundort hinaus exakt erfaßt. Aus Platzgründen kann hier auf die beiden Datierungsmethoden nicht näher eingegangen werden, und es sei deshalb auf die erwähnte Literatur verwiesen.

\subsection{Lage und Merkmale}

Fossile Hölzer, sofern vorhanden, können im Gletschervorfeld sowohl in den zum Teil steilen Ufermoränen als auch im flacher ausgebildeten Teil des Vorfeldes gefunden werden. Zwei Varianten seien hier kurz beschrieben:

Bäume, die den Kamm und die Außenseite der Ufermoräne besiedeln, können bei einem Gletschervorstoß von herunterfallenden Felsblöcken umgedrückt, vom Moränenschutt zugedeckt und so in den Moränenwall eingebettet werden (Abb. 1a). Während einer darauffolgenden Schwundphase des Gletschers kommen durch die einsetzende Erosion an der gletscherwärtigen Seite der Ufermoränen, die häufig steil gegen den Gletscher hin abfallen, solche Baumstämme wieder zum Vorschein (Abb. 1c). Holzfunde in verschiedenen Höhenlagen innerhalb des Profils dokumentieren verschiedene Gletschervorstöße. Oft ist an solchen Fundstellen der gleichzeitig mit dem Baum überschüttete Boden ebenfalls aufgeschlossen (RÖTHLISBERGER F. 1976; BLESS 1982: 187-194). Die Eishöhe des Gletschers bei der jeweiligen Vorstoßphase kann aufgrund der Lage des Holzes im Profil abgeleitet werden. In den meisten Fällen handelt es sich um Vorstoßphasen, welche die Größenordnung eines Hochstandes erreicht haben, obwohl das fossile Holz unterhalb des Niveaus von 1850 liegt (Abb. 1c). Das Gletscherbett hat sich nämlich bei solchen Gletschern während der verschiedenen Vorstöße immer etwas erhöht (SCHNEEBELI 1976: 26, 27).

Im Gletschervorfeld wachsende Bäume werden von einem vorstoßenden Gletscher häufig entwurzelt, teilweise wegtransportiert und einsedimentiert (Abb. 1b). Wie Untersuchungen von RÖTHLISBERGER F. (1976) zeigen, liegen die fossilen Baumreste im Gletschervorfeld oft unter einer mehrere Meter mächtigen Schuttdecke und können nur mittels künstlicher Aufschlüsse geborgen werden. Aber auch durch Schmelzwässer, die sich ins Moränenmaterial eingraben, werden fossile Bäume freigelegt (Abb. 1d). Durch Gletscherbäche und weitere Gletschervorstöße oft mehrfach umgelagert, sind solche fossilen Hölzer vielfach nicht mehr am Wuchsort zu finden. Entsprechend schwierig und problematisch ist deshalb die Auswertung von Holzfunden dieser Art, vor allem wenn es darum geht, minimale Gletscherausdehnungen $^{4}$ erfassen zu wollen. Auch die Möglichkeit, daß herumliegendes Holz durch Lawinen ins Gletschervorfeld gelangt, darf nie ganz ausgeschlossen werden (vgl. HESS 1935). Eine Abklärung, ob die Holzfund- 


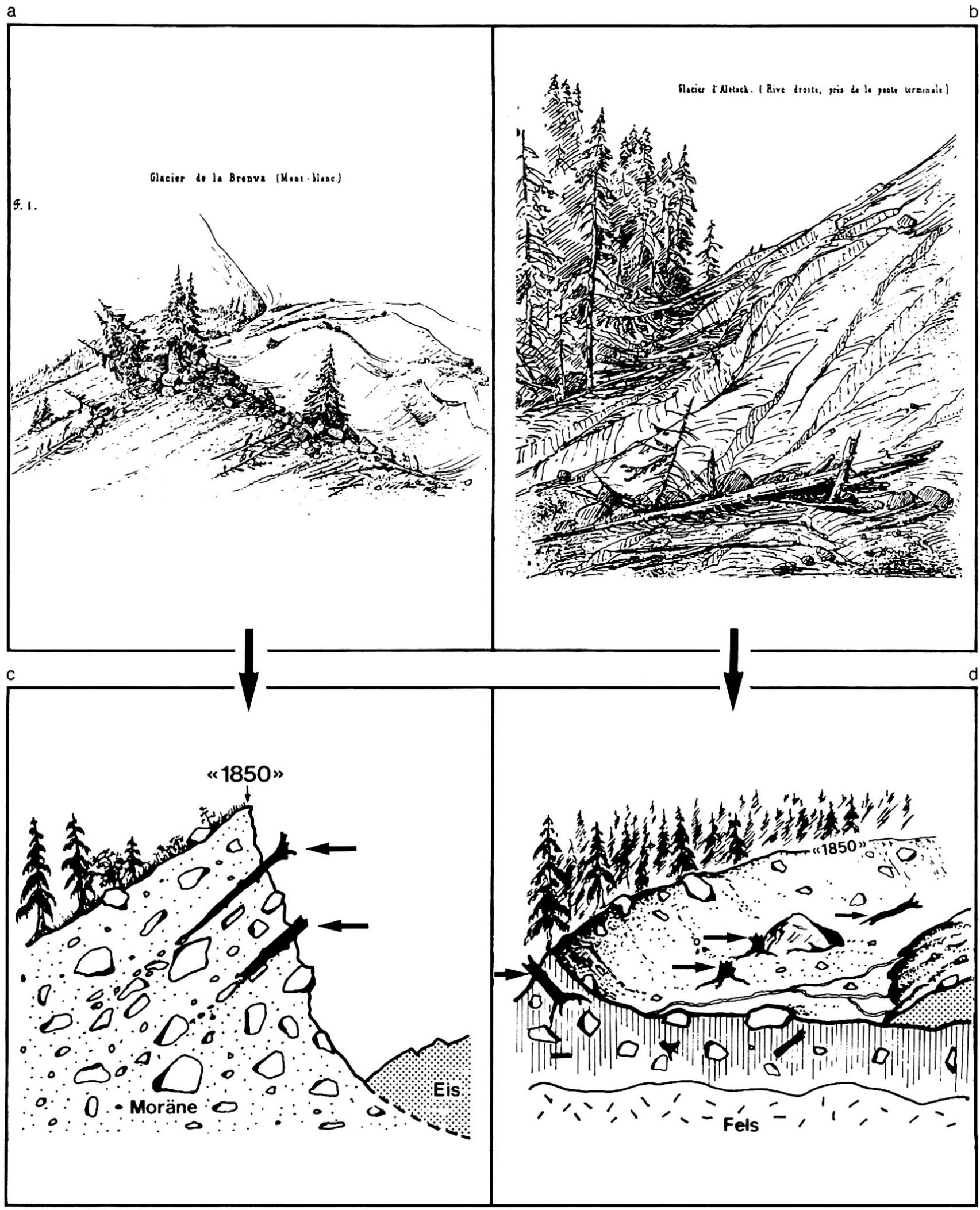

Abb.1 Umdrücken von Bäumen durch einen Gletscher und Lagerung fossiler Bäume im Gletschervorfeld:

a) "Moraine latérale droite du glacier de la Brenva, au pied du Mont-Blanc (versant de Courmayeur). Cette Moraine barrant presqu'entièrement le vallon de Frène dans l'Allée Blanche, était partiellement recouverte de grands sapins que le glacier renverse aujourd'hui." Zeichnung von H. Hogard, 1849.

(Aus: HOGARD 1858: 316/17, Planche 21/Fig.1). b) «Empiétements du glacier d'Aletsch, sur la forêt peuplée de vieux sapins (rive droite de la vallée), près de la pente terminale." Zeichnung von $\mathrm{H}$. Hogard, 1849. (Aus: HOGARD 1858: 319, Planche 31)

c) Ufermoräne: Profil mit fossilen Bäumen (Pfeile).

d) Gletschervorfeld: Profil/Aufsicht mit fossilen Wurzelstöcken in situ und fossilen Stämmen (Pfeile). 
stelle an einem ausgesprochenen Lawinenhang liegt, ist unumgänglich. Oft kann eine einheimische und ortskundige Person hier weiterhelfen.

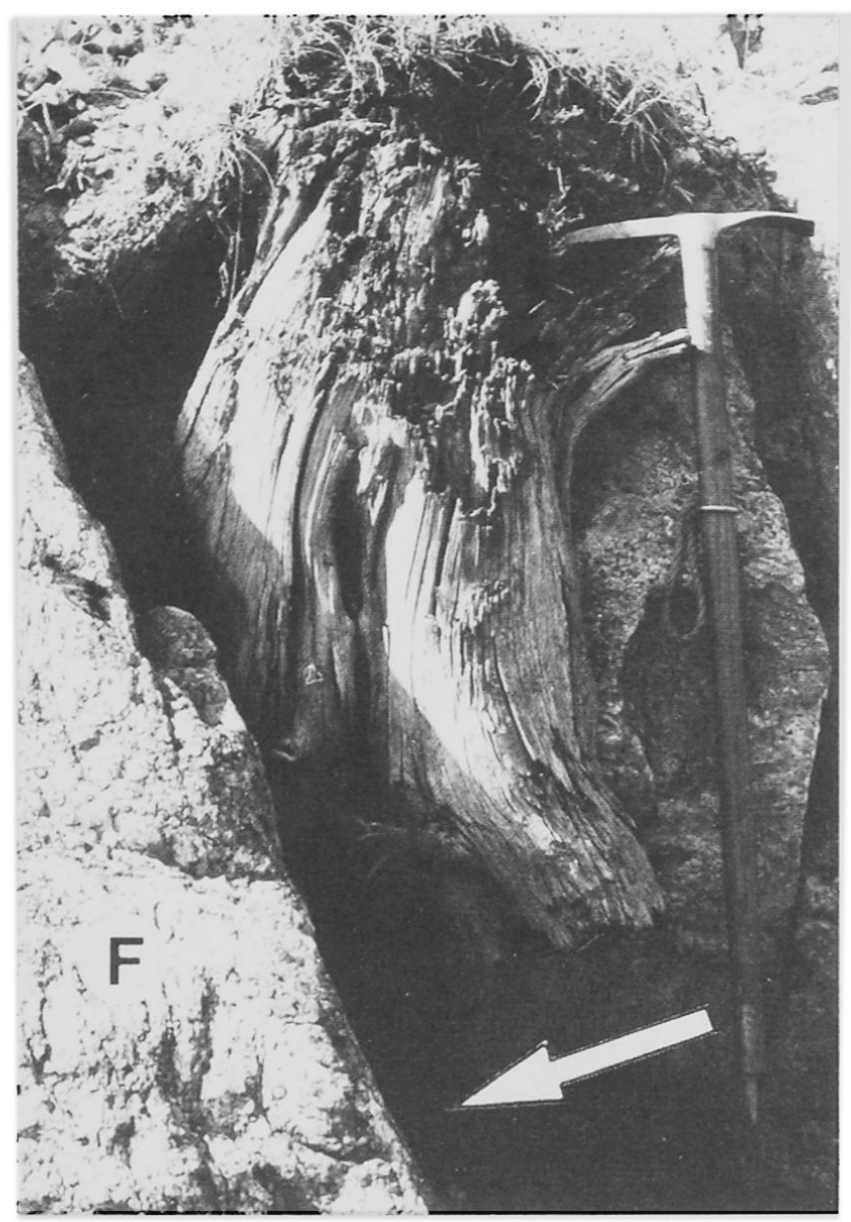

Abb. 2 Fossiler Wurzelstock einer Lärche in situ mit Gletscherschliff. Die äußersten Jahrringe weisen ein Radiokarbonalter von $625 \pm 65$ yBP (UZ-534) auf. Pfeil: Fließrichtung des Eises. F: anstehender Fels.

Die im Laufe meiner Feldarbeiten entdeckten fossilen Wurzelstöcke in situ (am Wuchsort) - teilweise mit einem Teil des Stammes - am Großen Aletschgletscher befanden sich zu einem Großteil im Schutze eines anstehenden Felskörpers. Sowohl im Luv als auch im Lee solcher aus dem umliegenden Gelände sich abhebenden Felsen waren fossile Hölzer in situ auszumachen. Diejenigen Baumteile, die den Felskörper überragten, wurden vom Gletscher weggedrückt. Die Wurzelstöcke sind vom Eis und dem darin enthaltenen Gesteinsmaterial oberflächlich abgeschliffen (Abb. 2). An verschiedenen Orten überdauerten nurmehr einige Wurzelfragmente in Felsritzen; andererseits wurden ganze Stammstücke gefunden. In der Regel lagen sie in Felsrinnen oder eingebettet in einem Hochstandsmoränenwall (Abb. 1d).
Das fossile $\mathrm{Holz}$ ist größtenteils sehr gut erhalten geblieben, was in einigen Fällen eine dendrochronologische Auswertung erlaubte. Der gute Erhaltungszustand ist einerseits auf die konservierende Wirkung des Eises, andererseits auf die Konservierung im Moränenschutt zurückzuführen. Auch spielen die klimatischen Einflüsse (trocken, naß) und der Standort des Baumes keine unbedeutende Rolle. SCHWEIN. GRUBER (1978: 192) bemerkt, daß Baumstämme aus alpinen Moränen weitgehend rezentem Holz entsprechen und in jeder Hinsicht jahrringanalytisch ausgewertet werden können.

Ein besonders charakteristisches Merkmal von fossilen Bäumen, die während eines Gletschervorstoßes umgedrückt wurden, ist ein mehr oder wenig plötzliches Auftreten von engen Jahrringen im peripheren Bereich des Stammes. An mehreren fossilen Hölzern aus dem Vorfeld des Großen Aletschgletschers kann dies beobachtet werden; im Durchschnitt fielen die äußersten 10 bis 20 Jahrringe eng aus. Feststellungen dieser Art haben schon LAWRENCE (1950: 245), SHARP (1958: 24) und auch OESCHGER und RÖTHLISBERGER H. (1961: 199) gemacht. Die Verengung der Jahrringe, einhergehend auch mit einer Verminderung der maximalen Spätholzdichte, ist im wesentlichen auf die veränderten lokalklimatischen Verhältnisse beim Herannahen des Gletschers zurückzuführen. $\mathrm{Zu}$ den zahlreichen Baumfragmenten aus dem Gletschervorfeld des Malaspina Glacier (Alaska) äußerte sich SHARP (loc. zit.) folgendermaßen:

"..., and nearly all show a marked restriction of ring width in the last 30 to 60 years of their life, as though heralding the approach of the glacier."

Bei LAWRENCE (loc. zit.) ist nachzulesen:

"A period when glacier ice was very close to a tree may also be evident in the growth layer pattern, through marked reduction in the thickness of the rings produced when ice was nearby even though the ice did not actually touch the tree."

An zwei Holzproben aus meinem Untersuchungsgebiet kann das Merkmal der sich verengenden Jahrringe sehr gut illustriert werden. Bei dem ersten Beispiel handelt es sich um eine fossile Lärche, die vom Großen Aletschgletscher während der Vorstoßphase gegen 1600 erfaßt und umgedrückt wurde (s. Kapitel 2.3.2). Mit Hilfe der Dendrochronologie wurde die Lebensdauer des Baumes bestimmt; er lebte von 1455 bis 1588 . Von besonderem Interesse ist die plötzlich einsetzende Verengung der Jahrringe ab dem Jahr 1504 (Abb. 3). Zu diesem Zeitpunkt mußte der Große Aletschgletscher sich in die Nähe der Lärche vorgeschoben haben, ohne jedoch die Ausdehnung von 1920 - dem Niveau des Baumstandortes - überschritten zu haben. Im Laufe der folgenden 84 Jahre veränderte sich der Eisstrom kaum wesentlich. Erst gegen 1588 stieß er kräftig vor, als Folge der Klimaänderung, die um die Jahre 1560/1570 ihren Anfang nahm (PFISTER et al. 1978: 101, 102; HOLZHAU- 


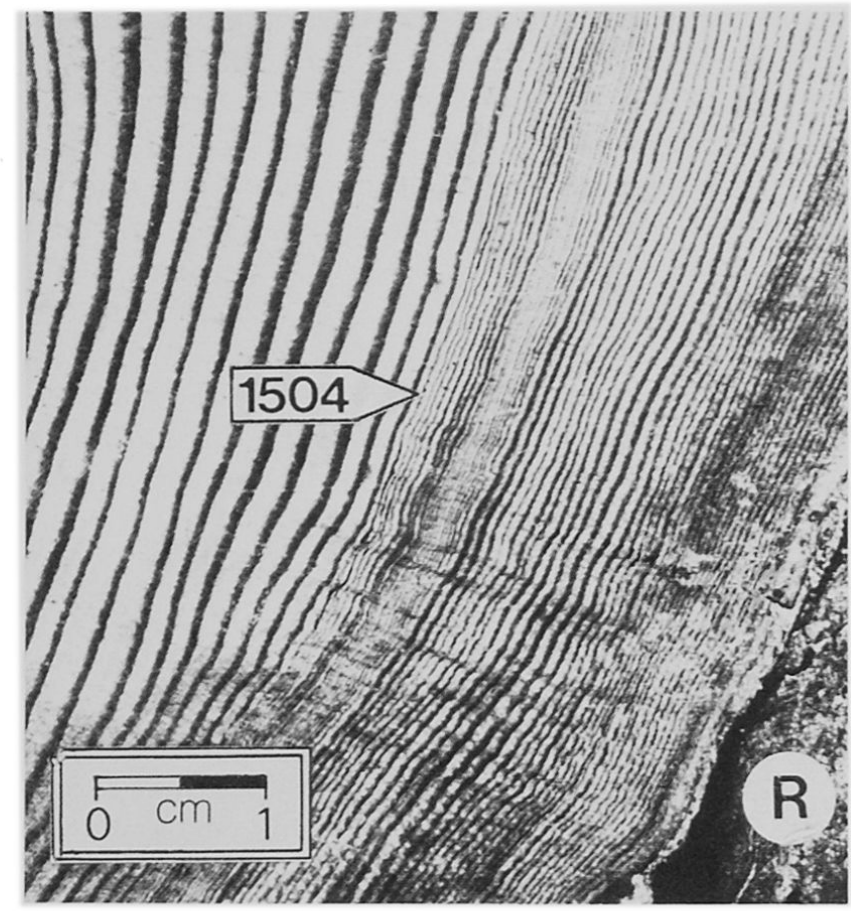

Abb. 3 Querschnitt durch eine fossile Lärche in situ, die vom Großen Aletschgletscher im Jahre 1588 umgedrückt wurde. Der Pfeil weist auf den Jahrring von 1504 hin, von dem an sich die Jahrringe deutlich verengen (Änderung der lokalklimatischen Verhältnisse durch Gletschervorstoß). R: Rinde.

SER 1982: 119). Das Eis verletzte den Baum zuerst im Wurzelbereich, was zur Ausbildung von zahlreichen Harzkanälen innerhalb der äußersten Jahrringe führte (vgl. dazu SCHWEINGRUBER 1978: 17). Erinnern wir uns des Zitates von Collomb (1849: 39), der schrieb:

«...La moraine latérale gauche les atteint, les attaque d'abord par les racines, puis, l'arbre tombe, ..."

Ein weiteres Beispiel zeigt die maximalen Spätholzdichte-Werte einer Fichte (Abb.4a). Der Baum lebt heute noch und steht nicht weit entfernt vom Hochstandsmoränenwall, den der Fieschergletscher um 1850 bildete (vgl. Abb. 4b). Der analysierte Bohrkern wurde mit einem Zuwachsbohrer an der 236 Jahre alten Fichte entnommen. Während der Gletscherhochstandsphase von 1820 bis 1860 fallen die Werte der maximalen Spätholzdichte durchgehend unterdurchschnittlich aus. Das Eis des Fieschergletschers lag während dieses Zeitraumes immer in der Nähe des Baumes. Wie den Aufzeichnungen von collomb (1849: 38) und einer Zeichnung mit Erläuterungen von HOGARD (1858: 326, Planche 20, Fig. 2) entnommen werden kann, warf der Fieschergletscher im Jahre 1849 in diesem Bereich Fichtenwald um.

\subsection{Gletschergeschichte im Spiegel fossiler Hölzer}

Den neuzeitlichen Hochstandsmoränen eng benachbart sind vielfach auch Moränenwälle älterer postglazialer Gletscherhochstände. Findet man durch Gra- bung fossile Böden oder fossile Hölzer unter den Hochstandswällen, können diese organischen Reste datiert und das Ereignis - die Aufschüttung des Walles durch den Gletscher - zeitlich eingestuft werden. Wohl ist nun die Ausdehnung des Gletschers während der betreffenden Zeit bekannt, nämlich ein Hochstand in der Größenordnung von 1850, über das Ausmaß des Vorstoßes jedoch - über den Vorstoßbe-
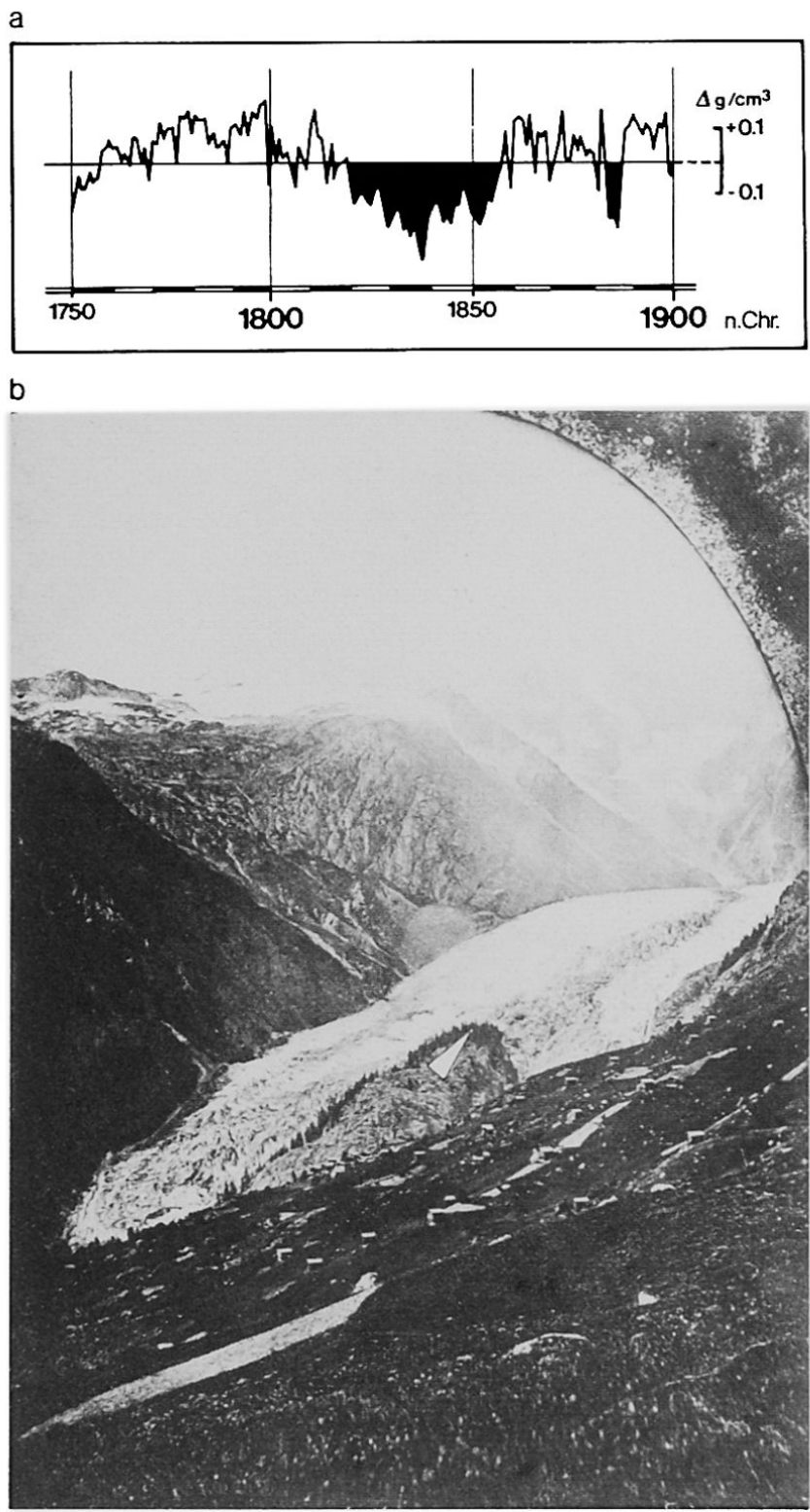

Abb. 4

a) Maximale Spätholzdichten einer Fichte von 1750 bis 1900 . Der Baum steht nahe der Hochstandsmoräne von 1850 . Die Jahrringe mit den tiefen Dichtewerten von zirka 1820 bis 1860 entstanden in der Zeit, als der Fieschergletscher im Hochstandsbereich stirnte.

(Radiodensitometrische Analyse: E. SCHÄR, EAFV Birmensdorf/ZH)

b) Der Fieschergletscher im Jahre 1850. Der Pfeil bezeichnet den Standort der Fichte.

(Aufnahme: D.DOLLFUS-AUSSET; Archiv der Gletscherkommission 
trag - läßt sich nichts aussagen, da wir in den meisten Fällen die Lage der Gletscherzunge vor dem betreffenden Vorstoß nicht kennen.

In der Neuzeit haben beispielsweise viele Gletscher während der Vorstoßphase von 1820 die Ausdehnung früherer Hochstände, zum Beispiel diejenige von $1600 / 1650$, erreicht und teilweise gar überschritten. Die Ursache, welche zu diesem kurzen, aber kräftigen Vorstoß führte, ist in einer Klimaschwankung zwischen 1812 und 1817 zu suchen, die durch naßkalte Verhältnisse gekennzeichnet war (PFISTER 1980: 188). Der kurzfristige Vorstoß um 1820 läßt sich aber nicht vergleichen mit demjenigen um 1600 , dem eine Reihe von klimatisch unterdurchschnittlichen Jahrzehnten vorangingen: Die Gletscherzunge lag bei allen untersuchten Gletschern vor 1820 weiter vorne als vor Beginn der Gletscherhochstandsphase von 1600/1650, dennoch liegen die Moränenwälle der beiden Vorstöße dicht neben- oder gar übereinander. PFISTER et al. (1978: 104) schreiben diesbezüglich:

"Angesichts der weit vorgeschobenen Ausgangsposition vieler Gletscher beim Beginn dieser Schwankung (von 1812-1817, eigene Anm.) wird verständlich, weshalb eine fünfjährige klimageschichtliche Episode in den Gletschervorfeldern nahezu dieselben Spuren hinterlassen hat wie ein Vorgang in der Größenordnung von mehreren Dezennien. Es zeigt sich deutlich, daß die klimageschichtliche Interpretation eines Moränenbefundes, was die Dauer und die Intensität der beteiligten klimatischen Prozesse anbetrifft, offenbar recht großen Spielraum offen läßt."

Die Problematik besteht offenbar darin, daß wir über minimale Gletscherausdehnungen während früherer Schwundphasen und damit über die Ausgangslage der Gletscherzunge vor einem Vorsto $B$ nur mangelhaft oder gar nicht im Bilde sind. Für das Ausleuchten der Gletschergeschichte innerhalb der letzten rund 300 Jahre können historische Dokumente in bezug auf kleinere Ausdehnungen als bei einem Hochstand Hinweise liefern (ZUMBüHL 1980). Da aber die Informationsdichte gegen 1600 und darüber hinaus in noch frühere Jahrhunderte stark abnimmt, ist unser Wissen über das damalige Gletscherverhalten und damit auch über Minimalausdehnungen ausgesprochen lückenhaft.

Mit Hilfe von fossilen Bäumen, die im Gletschervorfeld in situ gefunden werden, ist uns die einmalige Möglichkeit gegeben, frühere Gletschervorstöße, von denen keine historischen Quellen berichten, sowohl zeitlich als auch in ihrem Ausmaß zu erfassen. Findet man zum Beispiel einen fossilen Wurzelstock in situ unmittelbar vor der heutigen Gletscherzunge, so läßt sich folgendes aussagen: Während der gesamten Wachstumszeit des Baumes war der Gletscher nie größer als heute. Die Annahme einer geringeren Ausdehnung drängt sich sogar auf, denn eine gewisse Entfernung vom Baumstandort zum Gletscherrand muß eingeräumt werden. Das Radiokarbonalter der äußersten Jahrringe, das Absterbealter des Baumes, gibt den Zeitpunkt des Gletschervorstoßes an. Findet man nun ein gleichaltriges fossiles $\mathrm{Holz}$ in einem Hochstandmoränenwall, so ist auch der Vorstoßbetrag bekannt: Der Gletscher überschritt zum Zeitpunkt x die heutige Ausdehnung, stieß anschließend weiter vor und erreichte einen Hochstand. Solche Information ist, wie eingangs erwähnt, von großer Bedeutung bei der klimatischen Interpretation eines Gletschervorstoßes. Können die fossilen Bäume zusätzlich absolut, das heißt mit Hilfe der Dendrochronologie jahrgenau datiert werden, so kann aus der Differenz der Absterbealter der beiden Bäume die Vorstoßgeschwindigkeit ermittelt werden.

Wie oben erwähnt, verfügen wir mit dem Baumalter ebenfalls über ein wichtiges Indiz: Die Anzahl Jahrringe eines fossilen Baumes gibt die Zeitspanne an, in welcher der Baumstandort nicht mit Eis bedeckt war. Diese Feststellung ist nicht neu, schrieb doch schon COLlomB (1849: 34), als er am Großen Aletschgletscher vom Eis erfaßte Bäume beobachtete, die bis zu 200 Jahre alt geworden sind:

"Il y a donc au minimum 200 ans que ce glacier n'a pas atteint la lisière de la forêt qu'il ravage aujourd'hui."

Folgende schematische Darstellung soll das Vorgehen bei der Rekonstruktion der Gletschergeschichte mit fossilen Hölzern in situ veranschaulichen (Fig. 1):

Die Datierungen ergaben verschiedene Absterbealter der Bäume 1-7. Die Daten liegen teilweise zeitlich weit auseinander, so daß mehrere Gletschervorstöße in Betracht gezogen werden müssen. Aufgrund ihrer Lage im Gletschervorfeld und der Lebensalter der Bäume lassen sich sowohl minimale als auch maximale Gletscherausdehnungen ermitteln. Auch können Vorstöße festgestellt werden, bei denen der Gletscher keinen Hochstand erreichte (Fig. 1, $V_{1}-V_{3}$ ). Im aufgeführten Beispiel dehnte sich der Gletscher zum Zeitpunkt $\mathrm{x}$ stark aus; Baum 1 wurde dabei umgedrückt. Wie weit der Gletscher über das Niveau des Baumstandortes hinaus vorstieß, ist ungewiss, denn weiter gegen die Hochstandsmoränen hin wurde kein Holz gefunden, das aus dem selben Zeitraum datiert. Es darf aber angenommen werden, daß der Gletscher nicht allzu lange nach dem Kulminationspunkt dieses Vorstoßes $\left(\mathrm{V}_{1}\right)$ wieder abschmolz, weil im Gletschervorfeld wieder Bäume Fuß faßten (Bäume 4 und 6). Baum 6 ist erst vor wenigen Jahren infolge des anhaltenden Abschmelzens des Gletschers zum Vorschein gekommen. Während seiner Lebenszeit wies folglich der Gletscher zum Zeitpunkt y eine geringere Ausdehnung auf als heute (Fig. 1, $\mathrm{M}_{1}$ ). Im Laufe eines erneuten Gletschervorstoßes $\left(\mathrm{V}_{2}\right)$ überfuhr der Eisstrom nacheinander Baum 6 und Baum 4. Kurze Zeit, nachdem Baum 4 unter den Gletscher geriet, sank die Gletscheroberfläche wiederum ab. Eine Ausdehnung wie um 1890 erreichte der Glet- 


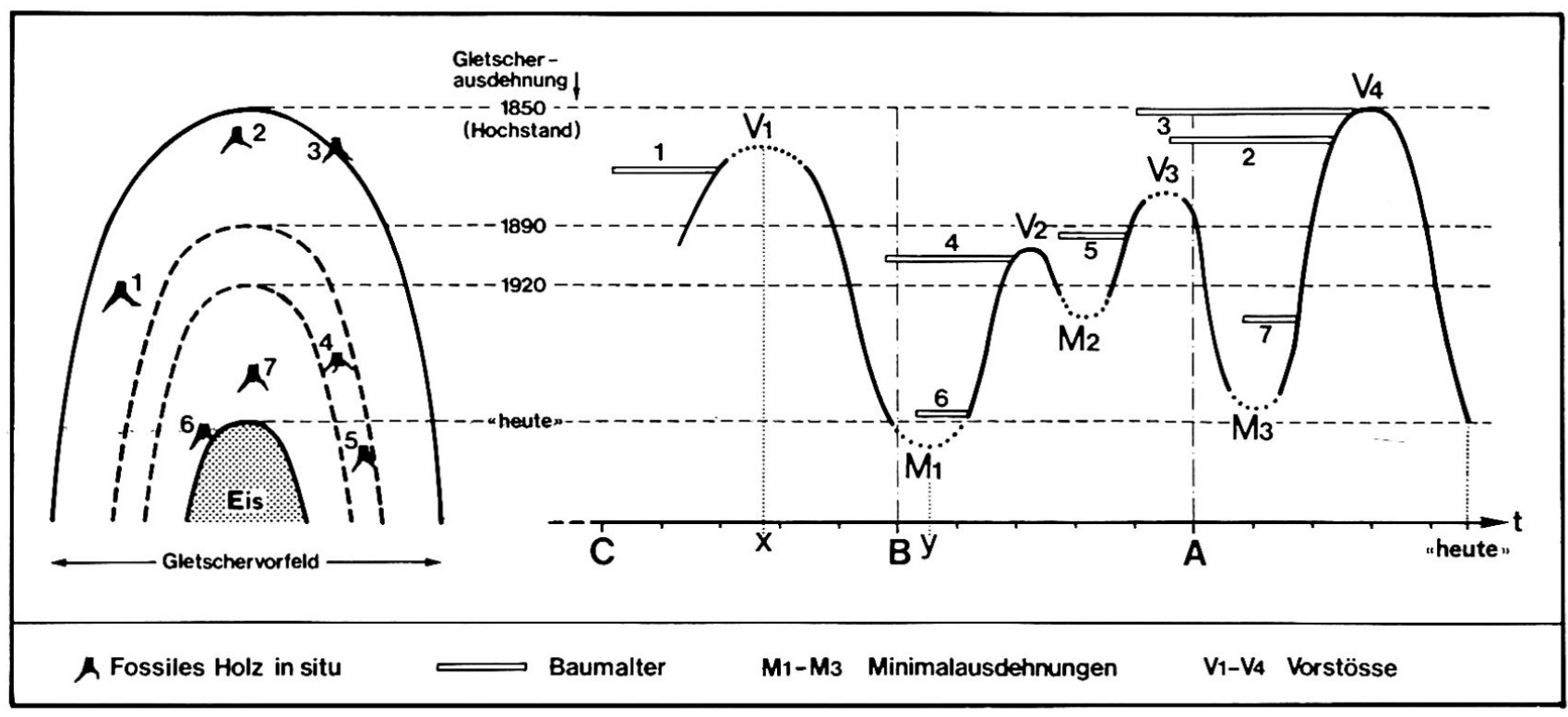

Fig. 1 Fossile Hölzer in situ, dendrochronologisch absolut datiert, und Gletscherschwankungen (Modellfall). Das Baumalter entspricht der Lebensdauer des Baumes (Anzahl Jahrringe).

scher nicht, da Baum 5 nicht lange Zeit, nachdem Baum 4 starb, zu wachsen begann und sein Standort eisfrei sein mußte. Der darauffolgende Gletschervorsto $B\left(V_{3}\right)$ drückte Baum 5 um und überschritt die Ausdehnung von 1890. Ein Hochstand ist aber auch hier nicht zu verzeichnen, denn die Bäume 3 und 2 waren auf einem höheren Niveau schon im Wachstum begriffen, als der Gletscher bei diesem Vorstoß seine größte Ausdehnung erreicht hatte. Der anschließend einsetzende Eisabbau erlaubte das Aufkommen von Baum 7 in einem Bereich des Gletschervorfeldes, welcher innerhalb der Ausdehnung von 1920 und dem heutigen Gletscherrand liegt. Dieser Baum lebte aber nur kurze Zeit; der Gletscher stieß, nachdem er eine Ausdehnung erreicht hatte, die in der Größenordnung der heutigen liegt (Fig. 1, $\mathrm{M}_{3}$ ), kräftig vor. Das Eis erfaßte zuerst Baum 7, kurze Zeit darauf Baum 2 und Baum 3; der Gletscher dehnte sich zu einem Hochstand aus.

Wie Fig. 1 zeigt, ist der Vorstoßbetrag bei den verschiedenen Vorstößen unterschiedlich. Ohne die fossilen Hölzer in situ hätten wir keinerlei Anhaltspunkte über Vorstöße, die kleiner waren als 1850 , weil die dazugehörigen Moränenwälle von späteren Gletschervorstößen in der Größenordnung von 1850 (Hochstand) zerstört wurden. Sind die fossilen Bäume dendrochronologisch absolut datiert (wie im vorliegenden Modellfall, Fig. 1), so können die einzelnen Gletschervorstöße zeitlich viel exakter bestimmt werden, als wenn nur ${ }^{14} \mathrm{C}$-Daten vorliegen.

Am Beispiel des Großen Aletschgletschers soll gezeigt werden, daß ein solch beschriebener Modellfall nicht nur in der Theorie existiert.

\subsection{Vorstoß-und Abschmelzphasen des Großen Aletschgletschers seit 1400 yBP}

Die folgenden Ausführungen beschränken sich auf den jüngsten Abschnitt der Kurve "Schwankungen des Großen Aletschgletschers seit 2500 yBP» (HOLZHAUSER, Dissertation im Druck) und umfaßt die mittelalterlichen und neuzeitlichen Gletschervorstöße beziehungsweise -schwundphasen. Insgesamt sind in diesem Kurvenabschnitt 35 Radiokarbondaten von fossilen Hölzern und ein Radiokarbondatum eines fossilen Bodens verarbeitet. Von den fossilen Bäumen sind sechs zusätzlich mit Hilfe der Dendrochronologie jahrgenau datiert. Die Rekonstruktion der Gletscherbewegung basiert ferner auf Hinweisen, die historischem Quellenmaterial entnommen werden konnten, und auf der Auswertung geländearchäologischer Spuren (alte Wasserleitungen und ehemalige Wege).

Ohne näher auf Details einzutreten, möchte ich die wesentlichen Resultate kurz umreißen, nicht zuletzt deshalb, weil zum ersten Mal mittelalterliche Gletschervorstöße auf das Jahr genau erfaßt werden konnten. Ebenso erlaubten die Ergebnisse es, Minimalausdehnungen zeitlich sowie räumlich festzulegen (vgl. Fig. 4).

\subsubsection{Mittelalterliche Gletschervorstöße}

Der Große Aletschgletscher stieß während des Mittelalters (500-1500 n. Chr.) viermal vor; um 1350 nahm er sogar die Ausmaße eines Hochstandes an.

Das erste Mal dehnte sich dieser Gletscher um 1300 yBP aus und erreichte eine Ausdehnung wie um 1890. Anschließend schmolz er stark ab. Die Gletscher- 


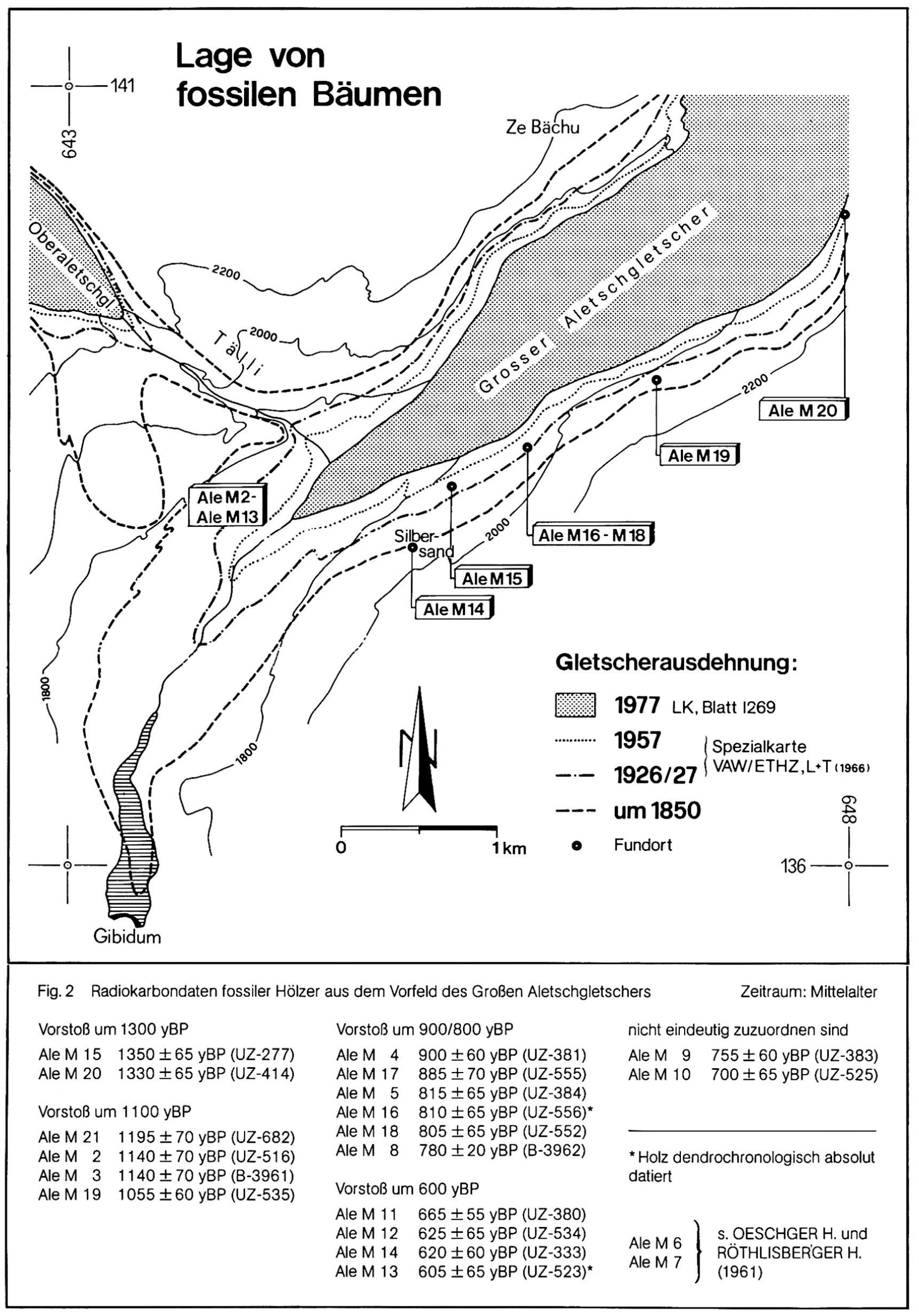


zunge lag bedeutend weiter talaufwärts als heute. Unweit der aktuellen Gletscherzunge konnten nämlich im Jahre 1982 verschiedene Baumreste in situ geborgen werden, unter anderem ein Lärchenstamm mit 51 Jahrringen. Sein Absterbealter von $1195 \pm 70$ yBP (UZ-682) ${ }^{6}$ belegt den Beginn eines Gletschervorstoßes um 1200 yBP. Das weitere Anwachsen des Eises wird durch weitere Holzfunde in situ dokumentiert, deren ${ }^{14} \mathrm{C}$-Alter um 1100 yBP liegen (vgl. Fig. 2). Um $1055 \pm 60$ yBP (UZ-535) lag der Eisrand nahe den Hochstandsmoränen (Ausdehnung wie um 1880). Interessant als Vergleich sind Untersuchungen von OROMBELLI und PORTER (1982: 17), die einen Vorstoß des Glacier de la Brenva (Val Veni, Mont BlancGebiet) mit der Datierung eines fossilen Baumes aus der Ufermoräne, dicht unterhalb der Oberkante gelegen, um $1170 \pm 55$ yBP nachweisen konnten.

Um 973 n. Chr. hatte der Große Aletschgletscher ähnliche Ausmaße wie heute angenommen, so daß auf dem Niveau der Ausdehnung von zirka 1926/27 eine Arve gedeihen konnte (Abb. 5). Sie lebte bis etwa um 1100 (äußerster erhaltener Jahrring: 1096 n. Chr.). Der Baum wurde zu diesem Zeitpunkt während eines erneuten Gletschervorstoßes vom Eise erreicht, das den Baumstamm etwa einen Meter oberhalb des Wurzelansatzes wegdrückte und über den Strunk hinwegglitt. Am Fundort ist heute durch die Einwirkung der Erosion, die tiefe Runsen in den Moränenschutt gegraben hat, auch der ehemalige Boden aufgeschlossen worden sowie eine Einschwemmung von Holzresten im $\mathrm{cm}$-Bereich innerhalb einer Feinsedimentlage. Die ${ }^{14} \mathrm{C}$-Analyse ergab Alter von $805 \pm 65$ yBP (UZ-552) für den fossilen Boden und $885 \pm 70$ yBP (UZ-555) für die organische Einschwemmung. Die absolut datierte Arve in situ wurde peripher auf ein Radiokarbonalter von $810 \pm 65$ yBP (UZ-556) bestimmt. Dieses ${ }^{14} \mathrm{C}$-Datum für die äußersten Jahrringe weicht vom wahren Alter nur wenig $a b$, nämlich rund 40 Jahre (plus den Fehler von \pm 65 Jahren). Den ähnlichen Altern der drei Proben nach zu schließen, wurden Baum und Boden etwa zur gleichen Zeit vom Gletscher überfahren. Im selben Zeitraum sind vermutlich randglazial durch Schmelzwässer die Holzteilchen eingeschwemmt worden. Bei diesem Gletschervorstoß dürfte es sich um denjenigen handeln, den OESCHGER und RÖTHLISBERGER H. (1961) erstmals belegen konnten.

Das Eis überschritt anschließend das Niveau der Fundstelle nicht mehr wesentlich; die größte damals erreichte Gletscherausdehnung ist ungefähr mit der Ausdehnung von 1920 vergleichbar. Diese Annahme kann wie folgt begründet werden:

Auf einem tieferen Niveau, das etwas oberhalb des Gletscherrandes um 1957 liegt, fand ich im Laufe der Feldarbeiten einen weiteren Baumstrunk in situ, der absolut datiert werden konnte. Der Baum - es handelt sich um eine Lärche - wuchs im Zeitraum von 1184

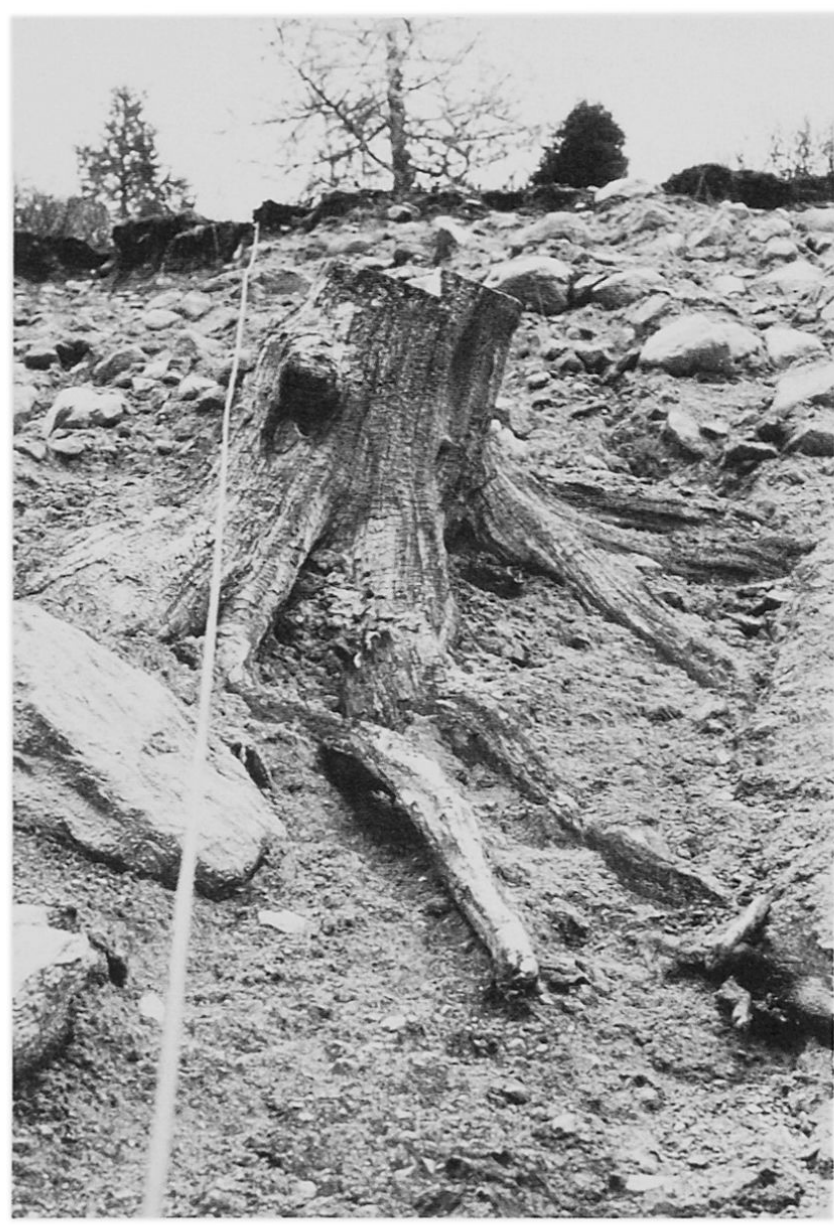

Abb. 5 Fossiler Arvenstrunk in situ. Die Arve lebte von 973-1096 und wurde während einer Vorstoßphase vom Großen Aletschgletscher überfahren.

bis etwa 1300 (äußerster erhaltener Jahrring: 1293 n. Chr.). Das Radiokarbonalter von $605 \pm 65$ yBP (UZ523) weicht vom absoluten Alter nur um 45 Jahre (plus Fehler von \pm 65 Jahren) ab. Die Lärche starb innerhalb einer Vorstoßphase, die durch weitere Holzfunde mit ${ }^{14} \mathrm{C}$-Altern um 600 yBP (vgl. Fig. 2) belegt ist. Es ist verständlich, daß der Große Aletschgletscher nicht allzu lange nach $1100 \mathrm{zu}$ schwinden begonnen haben mußte, so daß die erwähnte Lärche auf diesem tieferen Niveau überhaupt sich ansiedeln konnte. Der Gletscher wies in jener Zeit eine Ausdehnung auf, die der heutigen entspricht.

Der Vorstoß um 1300 und das anschließende Anwachsen des Gletschers können als äußerst kräftig bezeichnet werden, stirnte dieser doch um 1350 im Hochstandsbereich. Die Größenordnung dieses Vorstoßes ist derjenigen um 1100 yBP (zirka $850 \mathrm{n}$. Chr.) ähnlich. Große Gletscherausdehnungen um 1300/1350 sind schon von LUETSCHG (1926: 384) und LE ROY LADURIE (1967: 246, 247) aufgrund historischer Dokumente und von BORTENSCHLAGER und PATZELT (1973: 36-38) aufgrund morphologischer Befunde vermutet worden. 
Gletscherhochstände um 1300 sind in jüngster Zeit von BIRCHER (1982: 73-75) und von AESCHLIMANN (1983: 50, 51) direkt nachgewiesen worden.

Wie der Fig. 2 entnommen werden kann, sind die verschiedenen Vorstoßphasen im Mittelalter durch mehrere, etwa ähnliches Alter aufweisende fossile Hölzer belegt, die im unteren Abschnitt des Vorfeldes beidseitig des Gletschers gefunden wurden. Dieser Umstand erscheint mir wichtig. Um einen Gletschervorsto $B$ wahrscheinlich zu machen, bedarf es mehrerer gleichaltriger Hölzer, die über eine große Fläche im Gletschervorfeld verteilt sind. Nur so hat man die Gewißheit, daß die Bäume einem größeren Ereignis, in unserem Falle einem Gletschervorstoß, zum Opfer gefallen sind.

\subsubsection{Neuzeitliche Gletschervorstöße}

Ein allgemeiner Überblick über die neuzeitliche Gletschergeschichte kann in einer früheren Nummer der Geographica Helvetica (HOLZHAUSER 1982) nachgelesen werden.

Nach dem letzten mittelalterlichen Vorsto $B$ mit Hochstand um 1350 sank die Oberfläche des Großen Aletschgletschers ab, seine Zunge verlagerte sich sukzessive wieder talaufwärts. Aufgrund der Daten von absolut datierten Bäumen ist es möglich, diese Abschmelzphase und den nachfolgenden Vorsto $B$ gegen 1600 mehr oder weniger genau aufzuzeichnen (vgl. Fig. 3):

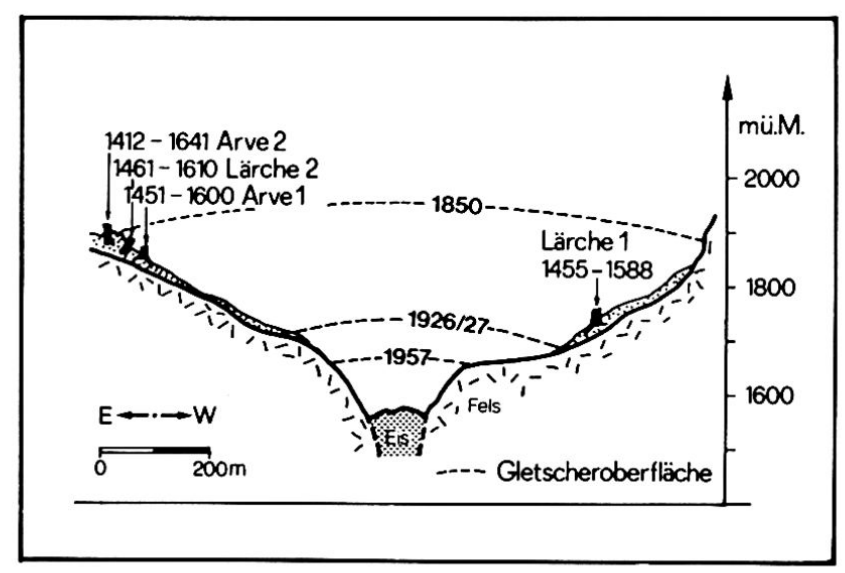

Fig. 3 Schematisches Profil im Bereich der Zunge des Großen Aletschgletschers. Eingetragen sind Lage und absolutes Alter von fossilen Bäumen.

Kurz nach 1400 , nämlich um 1412, lag die Gletscheroberfläche schon tiefer als zur Zeit des Hochstandes um 1350. Im Bereich der Hochstandsmoränen beginnt zu diesem Zeitpunkt eine Arve zu wachsen (Fig. 3, Arve 2). Im Jahre 1455 war der Gletscher bereits kleiner als um 1920, da auf dem Niveau von 1920 eine
Lärche Fuß faßte (Lärche 1). Arve 1, allerdings auf einem höheren Niveau, war um diese Zeit schon im Wachstum; nur wenig später, um 1461, siedelte sich auch Lärche 2 an. Der Große Aletschgletscher hatte folglich um 1455 schon gewaltig an Volumen eingebüßt. Im Vorfeld breitete sich allmählich wieder Wald aus, der höchstwahrscheinlich wie der heutige vorwiegend aus Lärchen zusammengesetzt war. Der Gletscher stirnte jedoch etwas weiter vorne als heute. Wie aufgrund von Alprechtsverträgen dargelegt werden kann, war der Große Aletschgletscher während des gesamten 15. Jahrhunderts nie wesentlich kleiner als um 1935/40.

Um 1504 dehnte sich der Gletscher ein wenig aus und schob sich in die Nähe von Lärche 1 (s. Fig. 3), die ab 1504 mit der Bildung von engen Jahrringen reagierte (Abb. 3). Diese verminderte Holzproduktion als Folge der geänderten lokalklimatischen Verhältnisse dauerte bis ins Jahr 1588 an. Zu diesem Zeitpunkt stieß der Große Aletschgletscher, nachdem er sich etwa 84 Jahre (von 1504-1588) mehr oder weniger im gleichen Zustand befunden hatte und nur geringfügig oszillierte, kräftig vor und drückte Lärche 1 um.

Das weitere Vorstoßen von 1588 an bis zum Hochstand um 1653 läßt sich anhand der Absterbealter von Arve 1, Lärche 2 und Arve 2 gut verfolgen (s. Fig. 3): Um 1600 war der Gletscher so groß wie um 1880; gegen 1610 dehnte er sich weiter aus, nahm um 1641 hochstandsähnliche Ausmaße an und erreichte um 1653 einen Hochstand. Aus dem Jahr 1653 datiert nämlich eine schriftliche Aufzeichnung über eine Prozession, die von den verängstigten Talbewohnern durchgeführt wurde, weil das Eis Kulturland zu zerstören begann. Insgesamt dauerte es rund 70 Jahre, bis der Große Aletschgletscher von einer Ausdehnung wie um 1920 bis zum Hochstand anwuchs. Der Vorstoß erfolgte jedoch nicht kontinuierlich. Von 1588 bis 1600 war er überaus kräftig; von 1610 bis etwa 1653 bewegte sich der Gletscher nurmehr langsam (Tabelle 1).

Zwischen dem ersten neuzeitlichen Hochstand um 1653 und der zweiten Hochstandsphase, die um 1820 einsetzte und bis über das Jahr 1850 hinaus andauerte, sank die Eisoberfläche sehr wahrscheinlich bis auf das Niveau von $1900 \mathrm{ab}$. Dieser Befund stützt sich auf Radiokarbondaten von fossilen Hölzern in situ (vgl. Fig. 4), die nach dem Hochstand von 1653 im Gletschervorfeld auf dem Niveau von 1880 und etwas darunter aufkamen und in der ersten Hälfte des 19. Jahrhunderts vom Gletscher überfahren wurden. Ihre ${ }^{14} \mathrm{C}$-Alter betragen $130 \pm 70$ yBP (UZ-276), 160 \pm 70 yBP (UZ-660) und $170 \pm 40$ yBP (UZ-412). Da die Bäume dendrochronologisch nicht auf das Jahr genau datiert werden konnten, muß offen bleiben, wann genau diese Bäume $z u$ wachsen begannen und wann genau sie vom Gletscher erfaßt wurden. Hinweise von historischem Quellenmaterial machen eine geringere Ausdehnung des Großen Aletschgletschers als um 


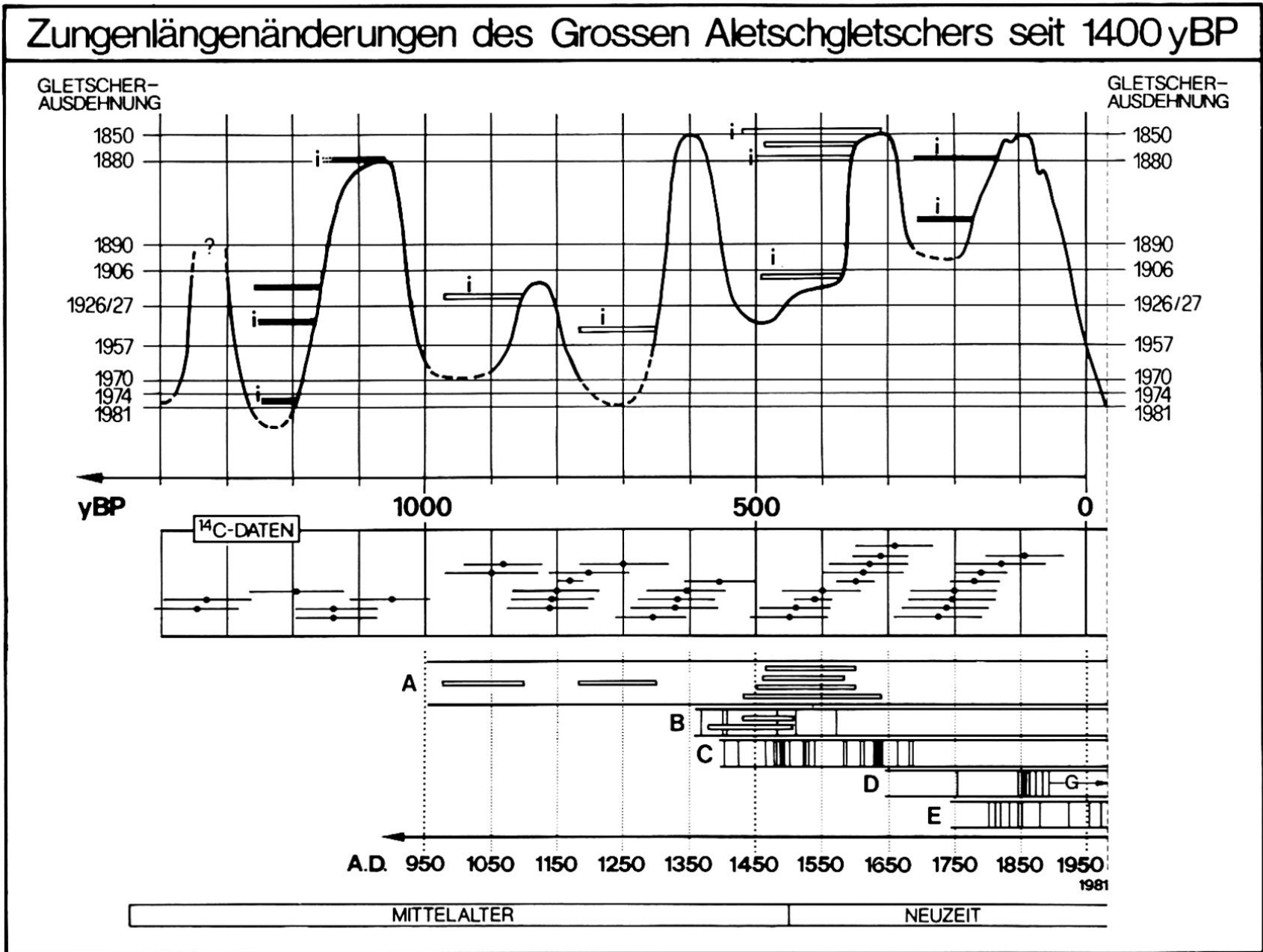
Fig. 4
$\longrightarrow{ }^{14} \mathrm{C}-$ Datum $( \pm$ l $\sigma)$
ש-Baumalter: ${ }^{\text {Absolut }}{ }^{14} \mathrm{C}$-datiert
i in situ
A Fossile Hölzer
B Wasserleitungen
C Alprechtsverträge
D Andere Schriftquellen
G Gletschervermessung
$\mathrm{E}$ Bildquellen
I Hinweis

1850 mindestens während der zweiten Hälfte des 18. Jahrhunderts wahrscheinlich (HOLZHAUSER, Geographica Helvetica 1/1980). Die lange Abschmelzphase, die nach dem Hochstand von 1850 einsetzte und heute noch andauert, wurde nur durch einen kleineren Vorstoß um 1891 (FOREL 1892: 300) unterbrochen. Um 1920 mußte sich der Große Aletschgletscher seitlich etwas expandiert haben, da im Gletschervorfeld beidseits des Gletschers auf dem Niveau von 1920 kleinere Moränenwälle auszumachen sind. Aufgrund der genauen Angaben von dendrochronologisch datierten Bäumen wurde versucht, die Vorstoßund Abschmelzgeschwindigkeiten des Gletschers in den verschiedenen Vorstoß- beziehungsweise Abschmelzphasen abzuschätzen. In Tabelle 1 sind diese Werte aufgeführt. Es muß aber betont werden, daß hier nur grobe Durchschnittswerte vorliegen. Ein gewisser Vorbehalt ist deshalb angebracht.
Tabelle 1

\begin{tabular}{|l|c|l|c|}
\hline Abschmelzphase & $\mathrm{m} / \mathrm{Jahr}$ & Vorstoßphase & $\mathrm{m} / \mathrm{Jahr}$ \\
\hline $1100-1184$ & $14-21$ & $1300-1350$ & $40-47$ \\
$1350-1455$ & $22-23$ & $1588-1653$ & $28-34$ \\
$1850-$ heute & 23 & $1588-1610$ & 70 \\
$1892^{\star}$-heute & 18 & $1610-1653$ & $4-5$ \\
\hline
\end{tabular}

*Beginn der Gletschervermessung

Die Abschmelzgeschwindigkeiten sind bei allen Schwundphasen etwa die gleichen; sie bewegen sich um $20 \mathrm{~m} / \mathrm{Jahr}$. Hingegen weisen die Vorstoßbeträge erhebliche Unterschiede auf, wie beispielsweise innerhalb der Vorstoßphase von 1588 bis 1653 . Wie groß der Einfluß der Topographie am Großen Aletschgletscher (enge Schlucht im Zungenbereich) zu den im Vergleich mit den Abschmelzwerten doch hohen Vorstoßbeträgen ist, müßte noch abgeklärt werden. 
Gehen wir davon aus, daß der Große Aletschgletscher ab heute wieder vorstoßen würde mit einer durchschnittlichen Geschwindigkeit von $40-47 \mathrm{~m} / \mathrm{Jahr}$ wie zwischen 1300 und 1350, so wäre ein Hochstand erst in 60-70 Jahren zu erwarten.

\section{Zusammenfassung}

Im vorliegenden Artikel wird gezeigt, wie mit Hilfe von fossilen Hölzern aus dem Gletschervorfeld minimale Gletscherausdehnungen und Gletschervorstöße erfaßt werden können. Einige zeitgenössische Berichte und Zeichnungen aus der Zeit um 1850, als die Alpengletscher ihren letzten neuzeitlichen Hochstand erreichten, sollen veranschaulichen, wie Gletscher in bewaldetes Gebiet vordrangen und Bäume umdrückten. Es wird im weiteren kurz auf die Lage von fossilem Holz im Gletschervorfeld und auf ihre wichtigsten Merkmale (guter Erhaltungszustand, Verengung der peripheren Jahrringe, Gletscherschliff) eingegangen. Ein konstruierter Modellfall veranschaulicht, wie fossiles $\mathrm{Holz}$ in situ gletschergeschichtlich ausgewertet werden kann. Als praktisches Beispiel dazu werden die Schwankungen des Großen Aletschgletschers seit 1400 yBP erläutert. Zum ersten Mal überhaupt konnten an einem Gletscher mittelalterliche Gletschervorstöße anhand dendrochronologisch absolut datierter Hölzer jahrgenau erfaßt werden. Ebenso kann mittels solch absoluter Datierungen die Vorstoßphase des Großen Aletschgletschers von 1588 bis 1653 relativ detailliert erfaßt werden.

\section{Literaturverzeichnis}

AESCHLIMANN, H. (1983): Gletschergeschichte in Italiens Mont Blanc-Gebiet, Val Veni - Val Verret - Ruitor. Diss. Univ. Zürich.

AGASSIZ, L. (1840): Etudes sur les glaciers. Neuchâtel.

BIRCHER, W. (1982): Beiträge zur Gletscher- und Klimageschichte des Saastales. Glazialmorphologische und dendroklimatologische Untersuchungen. Physische Geographie, Vol. 9, Zürich.

BLESS, R. (1982): Postglaziale Schwankungen des Glacier d'Argentière. Physische Geographie, Vol. 1: 187-194, Zürich.

BORTENSCHLAGER, S. und PATZELT, G. (1973): Die postglazialen Gletscher- und Klimaschwankungen in der Venedigergruppe (Hohe Tauern, Ostalpen). In: Z. für Geomorphologie, N. F. Suppl. Bd. 16: 25-72, Berlin und Stuttgart.

COLLOMB, E. (1849): De l'envahissement séculaire des glaciers des Alpes. Observations faites en août et septembre 1848, par E. Collomb. Supplément à la Bibliothèque universelle de Genève, Archives des sciences naturelles, Tome I, Genêve.

\section{Anmerkungen}

'Bei allen Jahreszahlen ohne nähere Bezeichnung handelt es sich um Jahre nach Christi Geburt.

${ }^{2}$ Unter dem Gletschervorfeld verstehe ich hier das Gelände zwischen dem aktuellen Gletscherrand und den postglazialen Hochstandsmoränen (s. dazu HOLZHAUSER, Geographica Helvetica 1/1982: 115, 116). Allgemein werden die Moränenwälle der neuzeitlichen Gletscherhochstände - ganz im Sinne KINZLs (1949: 82) - als äußere Vorfeldgrenzen genommen.

${ }^{3}$ AGASSIZ zitiert hier VENETZ und erwähnt, daß der Glacier de la Brenva 200- und 220jährige Lärchen umstieß. VENETZ (1833: 14) jedoch schreibt nur von den Resten einer Kapelle, die vom Gletscher kurz vor 1820 erreicht wurden:

"A. En Août 1820, nous avons observé que le glacier inférieur de l'Allée-Blanche n'avançoit déjà plus, ainsi que celui de Brenva qui avoit cédé 50 pieds de terrain après avoir atteint les ruines d'une chapelle, que M. de Saussure cite dans ses Voyages par les Alpes $\$ 855$.”

Es ist möglich, daß AGASSIZ die Information über die umgedrückten Bäume direkt von VENETZ oder anderweitig erhielt.

${ }^{4}$ Unter einer Minimalausdehnung verstehe ich hier die geringste Gletscherausdehnung zwischen zwei Gletschervorstößen (vgl. dazu Fig. 1).

${ }^{5}$ yBP bedeutet "years before Present" (Jahre vor heute, wobei hier mit "heute" das Jahr 1950 gemeint ist, das Basisjahr für Radiokarbondaten). 1400 yBP heißt also 1400 Radiokarbonjahre vor 1950 und entspricht folglich ungefähr dem Jahr 550 n. Chr. Geb. Die Radiokarbondaten sind mit einem Fehler von $\pm 1 \sigma$ Jahren behaftet, der ebenfalls angegeben wird ( $z$. B. $810 \pm 65$ yBP).

${ }^{6}$ Bei Radiokarbondaten ist es üblich, die Laborbezeichnung anzugeben. "UZ" ist die Bezeichnung für das ${ }^{14} \mathrm{C}$-Labor des Geographischen Institutes der Universität Zürich-Irchel, die angefügte Nummer bezeichnet die laufende Probennummer. "B» in Fig. 4 heißt, daß die Probe am Physikalischen Institut der Universität Bern datiert wurde.
FOREL, F.-A. (1892): Les variations périodiques des glaciers des Alpes suisses, 12. Rapport. Jb. des Schweizer Alpenclubs, 27. Jg., 1891/92, Bern.

FOREL, F.-A. (1902): Les variations périodiques des glaciers des Alpes suisses, 22. Rapport. Jb. des Schweizer Alpenclubs, 37.Jg., 1901/02, Bern.

GAMPER, M. und SUTER, J. (1982): Postglaziale Klimageschichte der Schweizer Alpen. In: Geographica Helvetica, 37.Jg., Nr. 2: 105-114, Zürich.

HESS, E. (1935): Holzfunde am Findelengletscher. In: Die Alpen, 11.Jg.: 281-290, Bern.

HOGARD, H. (1858): Recherches sur les glaciers et sur les formations erratiques des Alpes de la Suisse. Textband: Epinal; Tafelband: Paris.

HOLZHAUSER, H. (1980): Beitrag zur Geschichte des Großen Aletschgletschers. In: Geographica Helvetica, 35.Jg., Nr.1: 17-24. Kümmerly \& Frey, Bern. 
HOLZHAUSER, H. (1982): Neuzeitliche Gletscherschwankungen. In: Geographica Helvetica, 37.Jg., Nr. 2: 115-126, Zürich.

HOLZHAUSER, H. (im Druck): Zur Geschichte der Aletschgletscher und des Fieschergletschers. Diss. Univ. Zürich.

HOLZHAUSER, H. und WETTER, W. (1982): Auswertung historischer Quellen zur jüngsten Gletschergeschichte. In: Physische Geographie, Vol. 1: 49-60, Zürich.

KINZL, H. (1949): Formenkundliche Beobachtungen im Vorfeld der Alpengletscher. Sonderdruck aus Veröff. des Museums Ferdinandeum (Innsbruck), Bd.26/29, Jge. 1946/49: 61-82 (Klebelsberg Festschrift), Innsbruck.

LAWRENCE, D.B. (1950): Estimating dates of recent Glacier advances and recession rates by studying tree growth layers. In: Trans. Americ. Geoph. Union, Vol.31, Nr. 2: 243-248, Washington. LE ROY LADURIE, E. (1967): Histoire du climat depuis l'an mil. Flammarion; Paris.

LIBBY, W. F. (1952): Radiocarbon Dating. University of Chicago Press. Deutsche Übersetzung: Altersbestimmung mit der ${ }^{14} \mathrm{C}$ Methode. Hochschultaschenbücher-Verlag, Bibliographisches Institut, 1969, Mannheim und Zürich.

LUETSCHG, O. (1926): Über Niederschlag und Abfluß im Hochgebirge. Sonderdarstellung des Mattmarkgebietes. Ein Beitrag zur Fluß- und Gletscherkunde der Schweiz. Schweizer Wasserwirtschaftsverband, N. 14, Zürich.

MARIETAN, I. (1935/36): Restes de bois mis à découvert par le retrait du glacier d'Unteraar. In: Bull. de la Murithienne, Fasc. 53: 45-50, Sion.

MARIETAN, I. (1952): Fragments de bois trouvés aux glaciers de Ferpècle et du Mont-Miné. In: Bull. de la Murithienne Fasc. 69: 94-96, Sion.

OROMBELLI, G. and PORTER, S.C. (1982): Late holocene fluctuations of Brenva Glacier. Geogr. Fis. Dinam. Quat. 5: 14-37.

OESCHGER, H. und RÖTHLISBERGER, H. (1961): Datierung eines ehemaligen Standes des Aletschgletschers durch Radioaktivitätsmessungen an Holzproben und Bemerkungen zu Holzfunden an weiteren Gletschern. In: Z. Gletscherkd. Glazialgeol., Bd. 4, H. 3: 191-205, Innsbruck.
PFISTER, Ch., MESSERLI, B., MESSERLI, P. und ZUMBÜHL, H.J. (1978): Die Rekonstruktion des Klima- und Witterungsverlaufes der letzten Jahrhunderte mit Hilfe verschiedener Datentypen. In: Jb. Schweiz. Natf. Ges., wissenschaftl. Teil: 89-105. Birkhäuser Verlag, Basel, Boston und Stuttgart.

PFISTER, Ch. (1980): Klimaschwankungen und Witterungsverhältnisse im Mittelland und Alpenvorland zur Zeit des "Little Ice Age". Die Aussage der historischen Quellen. In: Das Klima: 175-190. Springer Verlag, Berlin, Heidelberg und New York.

RENNER, F. (1982): Beiträge zur Gletschergeschichte des Gotthardgebietes und dendroklimatologische Untersuchungen an fossilen Hölzern. Physische Geographie, Vol. 8, Zürich.

RÖTHLISBERGER, F. (1976): Gletscher- und Klimaschwankungen im Raum Zermatt, Ferpècle und Arolla. In: Die Alpen, 52. Jg., Nr. 3/4: 59-152, Bern.

SCHNEEBELI, W. (1976): Untersuchungen von Gletscherschwankungen im Val de Bagnes. In: Die Alpen, 52. Jg., Nr. 3/4 5-57, Bern.

SCHWEINGRUBER, F.H., SCHÄR, E. und BRAEKER, O.U. (1978): X-ray densitometric results for subalpine conifers and their relationship to climate. Dendrochronology in Europe, edited by John Fletcher, British Archaeological Reports, International Series 51: 89-100.

SCHWEINGRUBER, F.H. (1978): Mikroskopische Holzanatomie. Zürcher AG, Zug.

SCHWEINGRUBER, F. H. (1983): Der Jahrring. Standort, Methodik, Zeit und Klima in der Dendrochronologie. Verlag Paul Haupt, Bern und Stuttgart.

SHARP, R. P. (1958): The last major advance of Malaspina Glacier. In: Alaska. Geogr. Review, Nr. 1, Vol. XLVIII: 16-26, New York

VENETZ, I. (1833): Mémoire sur les variations de la température dans les Alpes de la Suisse. Par M. Venetz, ingénieur en chef du Canton du Valais. Rédigé en 1821. Denkschr. der allg. Schweiz. Ges. für die ges. Naturwiss. Bd. 1, Abt. 2: 1-38, Zürich.

ZUMBÜHL, H.J. (1980): Die Schwankungen der Grindelwaldgletscher in den historischen Bild- und Schriftquellen des 12. bis 19. Jahrhunderts. Birkhäuser Verlag, Basel, Boston, Stuttgart. 